\title{
Excision of anomalous muscle bundles as an important addition to extended septal myectomy for treatment of left ventricular outflow tract obstruction
}

\author{
Shuiyun Wang, MD, ${ }^{\mathrm{a}}$ Hao Cui, MD, ${ }^{\mathrm{a}}$ Qinjun Yu, MD, ${ }^{\mathrm{b}}$ Haibo Chen, MD, ${ }^{\mathrm{a}}$ Changsheng Zhu, MD, \\ Jingjin Wang, MD, ${ }^{\mathrm{c}}$ Minghu Xiao, MD, ${ }^{\mathrm{c}}$ Yanbo Zhang, $\mathrm{MD},{ }^{\mathrm{d}}$ Rong $\mathrm{Wu}, \mathrm{MD},{ }^{\mathrm{a}}$ and Shengshou $\mathrm{Hu}, \mathrm{MD}^{\mathrm{a}}$
}

\section{ABSTRACT}

Objective: This study aims to report our preliminary experience and anatomic findings in the surgical treatment and postoperative management of hypertrophic obstructive cardiomyopathy.

Methods: This study included 277 patients with hypertrophic obstructive cardiomyopathy (168 [60.65\%] were male), with a median age of 47 years (interquartile range, 35-54 years), who underwent surgical myectomy performed by 1 surgeon in Fuwai Hospital between May 2010 and April 2015. The median follow-up was 14 months (interquartile range, 7-24 months).

Results: A total of 127 patients (45.85\%) underwent concomitant procedures, and 2 patients $(0.72 \%)$ died in the early perioperative days. The left ventricular outflow gradient decreased from $78 \mathrm{~mm} \mathrm{Hg}$ (interquartile range, 61-100 $\mathrm{mm} \mathrm{Hg}$ ) to $11 \mathrm{~mm} \mathrm{Hg}$ (interquartile range, $8-15 \mathrm{~mm} \mathrm{Hg}$ ) when discharged $(P<.001)$. Of the 228 patients with well-documented anatomic description, more than $80 \%$ had various intraventricular anomalies. The cumulative survival was $99.28 \%$ (95\% confidence interval, 97.15-99.82) at 1 year and $96.98 \%$ (95\% confidence interval, 92.56-98.79) at 5 years. Of the surviving 272 patients, $268(98.53 \%)$ were categorized with functional class I and II of the New York Heart Association classification at the latest evaluation.

Conclusions: Anomalous muscle bundles are common in hypertrophic obstructive cardiomyopathy, and they may lead to middle-apical obstruction. Surgical myectomy provides excellent clinical outcomes with low risk for sufficient relief of obstruction and radical correction of intraventricular anomalies in patients with hypertrophic obstructive cardiomyopathy. (J Thorac Cardiovasc Surg 2016;152:461-8)

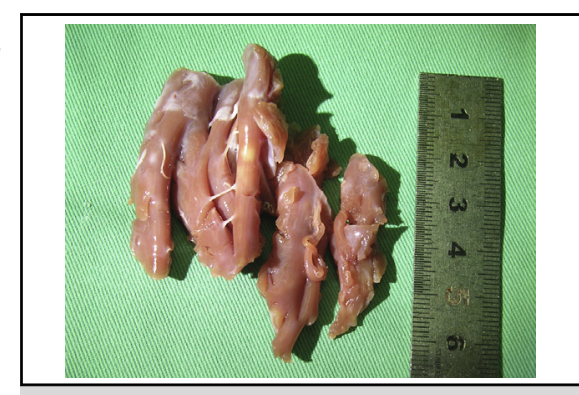

A whole piece of surgical specimen with anomalous muscle bundles. The weight of the largest piece was $13.6 \mathrm{~g}$, and the total was $17.5 \mathrm{~g}$.

\section{Central Message}

This study proves the favorable outcome of myectomy for HOCM and reports the details of classified intraventricular anomalies.

\section{Perspective}

Anomalous muscle bundles may be the leading cause of middle-apical obstruction in patients without evident septal hypertrophy. They may extend surgery indications for patients with middle-apical obstruction of the left ventricular outflow tract in the future. We hope this will draw some attention to the relationship between arrhythmia and anomalous muscle bundles in HCM.

See Editorial Commentary page 469
Hypertrophic cardiomyopathy (HCM) is a prevalent cardiac disease inherited as an autosomal dominant trait. HCM

\footnotetext{
From the Departments of ${ }^{\mathrm{a}}$ Cardiovascular Surgery, ${ }^{\mathrm{b}}$ Anesthesiology, and ${ }^{\mathrm{c}}$ Echocardiography, and ${ }^{\mathrm{d}}$ Intensive Care Unit, State Key Laboratory of Cardiovascular Disease, Fuwai Hospital, National Center for Cardiovascular Diseases, Chinese Academy of Medical Sciences and Peking Union Medical College, Beijing, China. This work was supported by Beijing Science and Technology Program (China): No. Z161100000516154, Capital Research Funds for Medical Development Project (China): 2011-4003-05, and National Natural Science Foundation of China: 81570276. Drs Wang and Cui contributed equally to this work.

Received for publication Sept 17, 2015; revisions received Jan 19, 2016; accepted for publication Jan 26, 2016; available ahead of print March 28, 2016.

Address for reprints: Shuiyun Wang, MD, No. 167, Beilishi Rd, Xicheng District, Beijing 100037, China (E-mail: wsymd@sina.com).

0022-5223

Copyright (C) 2016 by The American Association for Thoracic Surgery. Published by Elsevier Inc. This is an open access article under the CC BY-NC-ND license (http:// creativecommons.org/licenses/by-nc-nd/4.0/).

http://dx.doi.org/10.1016/j.jtcvs.2016.01.051
}

affects 1 in 500 of the total population ${ }^{1,2}$ and is the most common cause of sudden cardiac death (SCD) in young individuals. $^{3,4}$ The clinical phenotype of $\mathrm{HCM}$ varies from an asymptomatic state to severe heart failure complicated by SCD. Abnormal ventricular septal thickness, a characteristic pathologic phenotype of HCM, may lead to left ventricular outflow tract (LVOT) obstruction. Medication currently is the first-line therapy for the treatment of hypertrophic obstructive

Scanning this QR code will take you to the article title page.

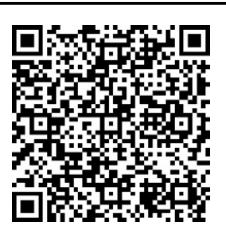




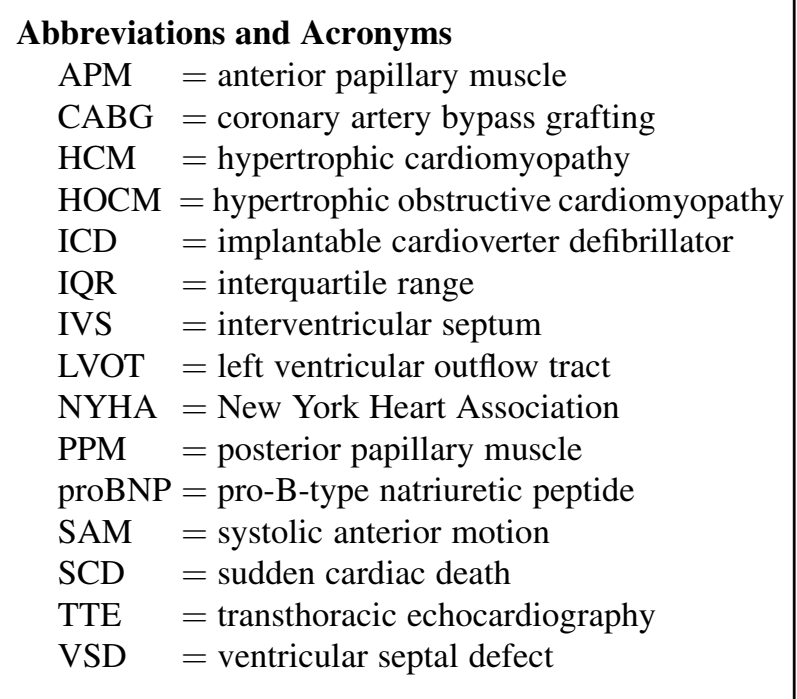

cardiomyopathy (HOCM). Nevertheless, relief of LVOT obstruction by invasive methods is unavoidable for patients with severe symptoms and refractory to maximum medical therapies. Recent guidelines have recommended that surgical septal myectomy is the gold standard for the treatment of HOCM. $^{5,6}$

Septal myectomy, also known as the "extended Morrow procedure," has evolved into a comprehensive repair technique for LVOT obstruction and abnormalities of the mitral apparatus over the past decades. ${ }^{7}$ Extension of the myectomy area and correction of mitral apparatus anomalies have considerably improved the surgical effect of this treatment. However, the anomalous intraventricular anatomy has not been fully revealed. Over the past several years, we have performed an extended septal myectomy in more than 250 patients with HOCM and identified a high prevalence of associated intraventricular anomalies. Compared with previous myectomy series in Fuwai Hospital, ${ }^{8}$ surgical reconstruction of the LVOT addressing these anomalies significantly improved the postoperative effect. In this article, we report our experience regarding the surgical treatment of HOCM.

\section{MATERIALS AND METHODS \\ Patients}

This study included 277 patients with HOCM who underwent septal myectomy by 1 surgeon (SW) at the Fuwai Hospital from May 2010 to April 2015. Indications of surgery included the following: (1) an LVOT pressure gradient of $50 \mathrm{~mm} \mathrm{Hg}$ or greater at rest or with physiologic provocation (mainly physiologic exercise), as determined under Doppler transthoracic echocardiography (TTE); and (2) presence of severe limiting symptoms refractory to maximum pharmacologic therapy. Meanwhile, patients who met the following criteria were not recommended to undergo operation: (1) aged more than 70 years, because we lack experience with these patients; and (2) the presence of an additional risk for on-pump cardiac surgery, which may lead to early postoperative death. The study was approved by The Ethics Committee of Fuwai Hospital, and all patients signed informed consent.

\section{Perioperative Evaluation}

Preoperative and postoperative TTE were performed to determine pressure gradient, ventricular septal thickness, mitral valve anomalies, and other necessary data. To guide intraoperative myectomy, we successively measured the septal thickness of the point $15 \mathrm{~mm}, 25 \mathrm{~mm}$, $35 \mathrm{~mm}$, and $45 \mathrm{~mm}$ under the right coronary sinus nadir. The point $25 \mathrm{~mm}$ under the right coronary sinus nadir was taken as a landmark point to represent the septal thickness. Intraoperative transesophageal echocardiography was conducted to guide the operation and report the real-time effect of the surgery. All patients underwent coronary angiography or coronary computed tomography angiography before the operation. Concomitant coronary artery bypass grafting (CABG) was performed when necessary. Preoperative and postoperative electrocardiography was conducted to detect heart block and other severe electrophysiologic disorders.

Surgical procedures. As described in our previous report, ${ }^{9}$ we used an extended septal myectomy, which evolved from the traditional Morrow procedure. The patient was put in the reverse Trendelenburg and left lateral prone position. After a median incision with sternotomy, cardiopulmonary bypass was performed using ascending aortic cannulation and venae cava cannulation. The aorta was transected approximately $7 \mathrm{~mm}$ above the right coronary ostium. The left-right sinus and right nonsinus commissures were elevated and retracted with 5-0 Prolene suture. Auxiliary light and loupe magnification were used to achieve better inspection of the left ventricular cavity. The resection ranges were as follows: The upper end was located at approximately $4 \mathrm{~mm}$ below the aortic ring; the lower end was extended to the apex of the left ventricle; from the right side, the myectomy was started slightly rightward to the nadir of the right aortic cusp; and to the left, resection was terminated near the mitral anterior commissure. Elongated leaflets were not routinely folded, unless severe regurgitation or systolic anterior motion (SAM) remained after resection. To obtain a more posterior position, partial excision of the papillary muscles off the left ventricular wall was necessary. Aberrant muscle bundles were resected, including aberrant muscle bundles located around the root of papillary muscles, between the apex and the left ventricular free wall, and between the papillary muscles and the free wall. In most cases, all anomalous chordae tendineae and muscle bundles were removed, and aberrant adhesions were detached. However, chordae and thin muscle bundles connecting anterior commissure and adjacent septum should be reserved if they exist. Secondary chordae that linked to the region of mitral leaflets near the ring were cut. After resections were completed, the bases of the papillary muscles should be seen by looking through the incision of the aortic root. Then, the LVOT and mitral valve were carefully and thoroughly reexplored. All inspection, exploration, and resection were carried out via a transaortic approach. Mitral repair or replacement was performed when necessary. According to preoperative examination and intraoperative exploration results, tricuspid repair, CABG, atrial fibrillation radiofrequency ablation, and other procedures were conducted appropriately. We routinely used bipolar clamp via biatrial access in atrial fibrillation ablation. Auricular appendectomy and amputation of the Marshall ligament were simultaneously performed with ablation. After weaning from cardiopulmonary bypass, immediate reoperation was performed if intraoperative transesophageal echocardiography detected a postoperative LVOT gradient of $30 \mathrm{~mm} \mathrm{Hg}$ or greater. To avoid reinitiation of cardiopulmonary bypass, we have the following intraoperative strategies: (1) create a smooth and plane septum with a touch-feeling of approximately $10 \mathrm{~mm}$ thickness; (2) release the papillary muscles to the apex; and (3) perform an intraoperative saline injection leak test in patients with preoperative moderate to severe concentric mitral regurgitation.

\section{Statistics}

Perioperative data were collected during the patients' hospital stay, and follow-up data were obtained by telephone questionnaire. Basic follow-up information included survival status, heart function, incidence of adverse 
events, postoperative treatment, and follow-up examinations. Nine patients $(3.25 \%)$ were temporarily lost to the cross-sectional follow-up; for these patients, we used the results of the last follow-up. The follow-up end point was all-cause mortality. Normally distributed data were provided as mean \pm standard deviation and compared with Student $t$ test. Continuous variables with skewed distributions were expressed as median (interquartile range [IQR]) and compared with Wilcoxon signed-rank test (related samples) or Mann-Whitney $U$ test (independent samples). Categoric data were compared by using the chi-square test. All reported probability values were 2-tailed. SPSS 22.0 Statistical Software (SPSS Inc, Chicago, Ill) and Prism GraphPad 5.0 (GraphPad Software Inc, La Jolla, Calif) were used for calculations and illustrations.

\section{RESULTS}

\section{Baseline Characteristics}

The baseline characteristics of the cohort are shown in Table 1. Patients in this group had a median age of 47 years (IQR, 35-54) during the operation. A total of 168 patients were male, and 19 patients in the cohort were aged 16 years or less. The median body weight was $68 \mathrm{~kg}$ (IQR, 57-77), and the median height was $166 \mathrm{~cm}$ (IQR, 158-172). All patients received beta-blocker or calcium channel blocker treatment before the operation. Most patients manifested severe limiting symptoms, such as dyspnea and stethalgia. Seven patients had previously undergone alcohol ablation, 52 patients had confirmed family history of HCM, and 38 patients had a family history of sudden death.

\section{Anatomic Features}

We recorded detailed anatomic features in the later 228 patients after we gradually recognized the intraventricular anomalies. The median weight of the operation specimens was $6.84 \mathrm{~g}$ (IQR, 5.18-9.26). Most of the 228 patients had anomalous muscle bundles or chordae tendineae. A

TABLE 1. Baseline characteristics

\begin{tabular}{lc}
\hline \multicolumn{1}{c}{ Characteristic } & Median value or number $(\mathbf{n}=\mathbf{2 7 7})$ \\
\hline Age $(\mathrm{y})$ & $47(\mathrm{IQR}, 35-54)$ \\
Male & $168(60.65 \%)$ \\
Body weight $(\mathrm{kg})$ & $68(\mathrm{IQR}, 57-77)$ \\
Height $(\mathrm{cm})$ & $166(\mathrm{IQR}, 158-172)$ \\
Heart rate (beats/min) & $76(\mathrm{IQR}, 70-80)$ \\
Blood pressure (mm Hg) & $115(\mathrm{IQR}, 108-120) / 70(\mathrm{IQR}, 65-80)$ \\
Preoperative symptoms & \\
Exertional dyspnea & $260(93.86 \%)$ \\
Stethalgia & $116(41.88 \%)$ \\
Amaurosis & $42(15.16 \%)$ \\
Syncope & $62(22.38 \%)$ \\
Medical therapy & \\
Beta-blocker & $271(97.83 \%)$ \\
Calcium blocker & $171(61.73 \%)$ \\
Previous alcohol ablation & $7(2.53 \%)$ \\
Confirmed family history of HCM & $52(18.77 \%)$ \\
Family history of sudden death & $38(13.72 \%)$ \\
ICD implantation & $0(0 \%)$ \\
\hline$I Q R$, Interquartile range; $H C M$, hypertrophic cardiomyopathy; ICD, implantable \\
cardioverter defibrillator.
\end{tabular}

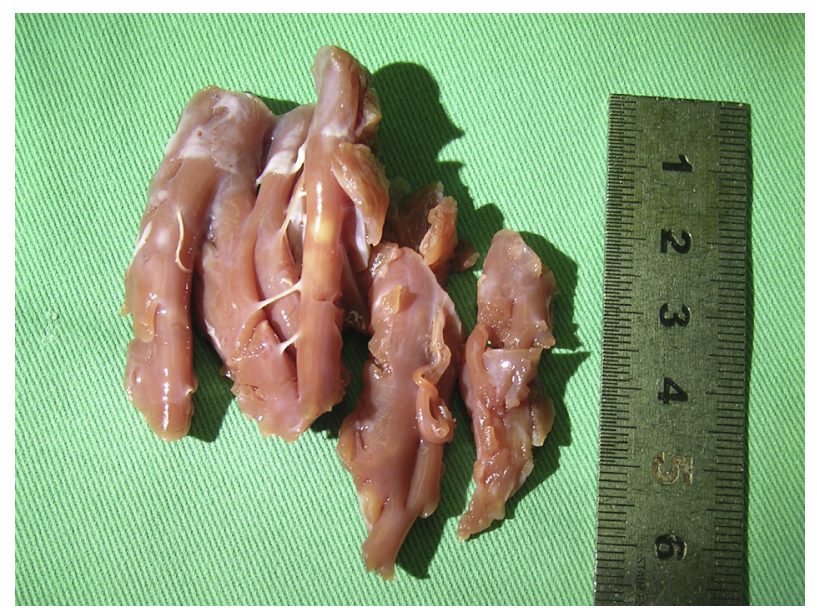

FIGURE 1. A whole piece of surgical specimen with anomalous muscle bundles. The weight of the largest piece was $13.6 \mathrm{~g}$, and the total was $17.5 \mathrm{~g}$.

representative specimen with anomalous muscle bundles or chordae tendineae is shown in Figure 1. The anomalies observed generally were divided into 4 types: (1) anomalous muscle bundles (Figure 2, Al-A3) between the interventricular septum (IVS) and other myocardial parts, including the ventricular apex, anterior papillary muscle (APM), and posterior papillary muscle (PPM); (2) APM or PPM adhesion to the IVS and left ventricular wall; (3) accessory muscles that originated from the APM (Figure 2, B1-B3), PPM (Figure 2, C1-C3), or IVS were directly inserted into leaflets; and (4) anomalous tendinous chordae linkage to IVS. As shown in Table 2, the most shared anomaly was aberrant muscle bundles between the ventricular apex and the IVS, which occurred in approximately three quarters of the patients. More than one half of the patients had anomalous muscle bundles connecting IVS and papillary muscles. Thirty-five patients presented adhesion to the IVS of papillary muscles or their fusion. Abnormal linkage with tendinous chordae was another commonly seen anomaly and detected in 101 patients. Further analysis showed that adhesion and anomalous muscular linkage more frequently occurred in bodies of papillary muscles than in head parts, whereas tendinous chordae linkage exhibited the opposite trend. In addition, excrescent muscle bundles in the apical ventricle area were detected in most patients, all of whom underwent resection. In some patients, the septum was covered with thick fibrous membrane, and thus case dissection was performed.

\section{Concomitant Procedures}

After thorough preoperative assessment and careful intraoperative investigation, 150 patients (aged 44 years [IQR, 33-53]) underwent isolated myectomy, and 127 patients underwent concomitant procedures (Table 3). Main 


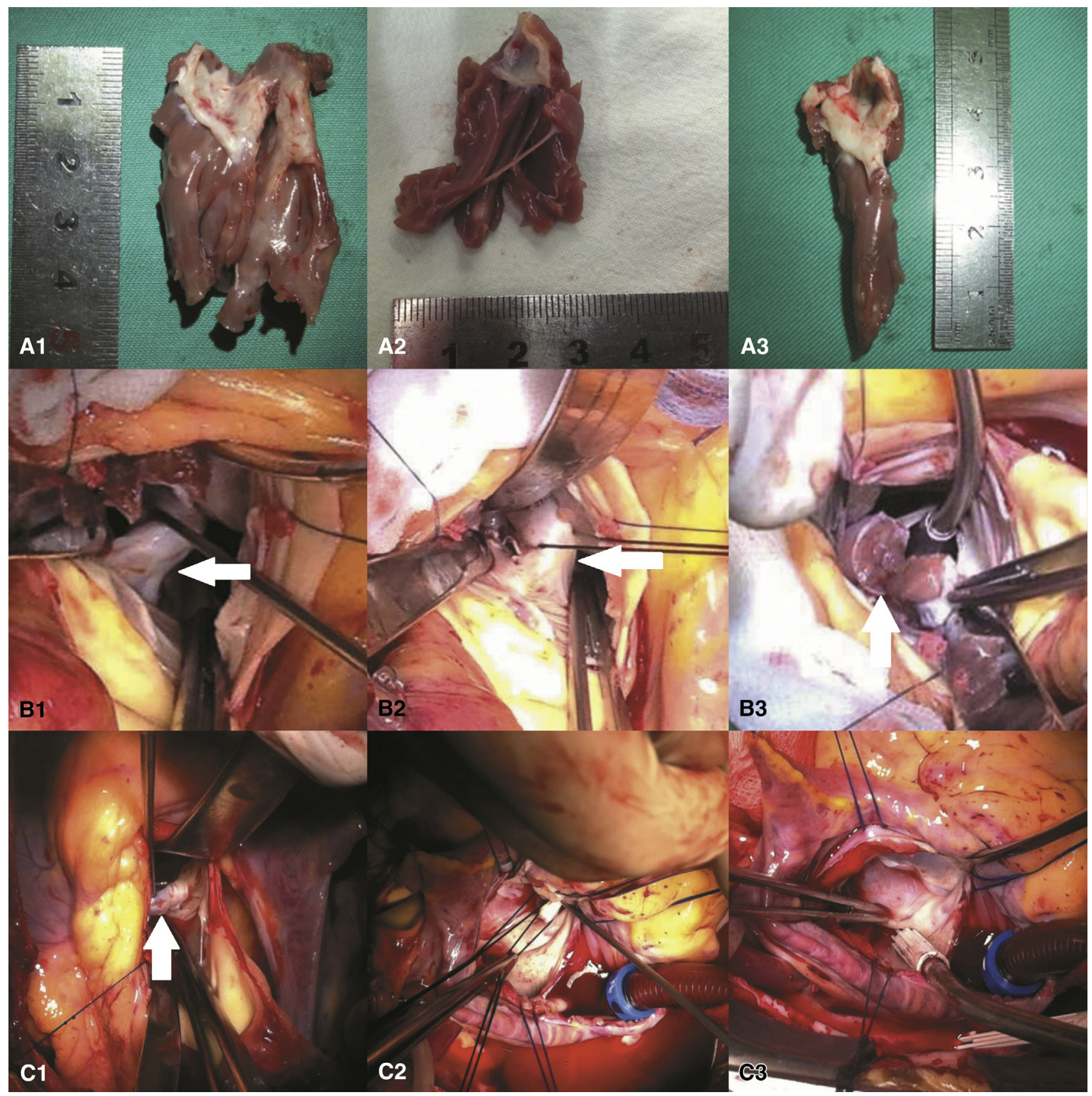

FIGURE 2. Anomalous muscle bundles. A1-A3, Surgical specimen with anomalous muscle bundles. B1-B3, Accessory APM (white arrow) directly inserted into A1 leaflet. C1-C3, Abnormal PPM (white arrow) directly inserted into A3 leaflet.

concomitant procedures were CABG in 47 patients (aged 47 years [IQR, 37-55]); tricuspid valvuloplasty in 42 patients (aged 51 years [IQR, 44-64]); mitral valvuloplasty or mitral valve replacement in 59 patients (aged 51 years [IQR, 46-61]); and radiofrequency ablation-modified maze procedure in 18 patients (aged 50 years [IQR, 44-57]). A total of 23 patients underwent double-orifice mitral repair; 10 patients underwent prosthetic ring implantation; 8 patients underwent double-orifice plus prosthetic ring implantation; 3 patients underwent quadrangular resection plus prosthetic valve ring implantation; and 1 patient underwent double-orifice repair, quadrangular resection, and prosthetic valve ring implantation. Mitral replacements mainly were related to irreparable lesions, including subacute bacterial endocarditis in 8 patients and severe mitral valve calcification in 6 patients. A total of 43 patients had coronary myocardial bridge detected by angiography or computed tomography angiography. Among the patients who underwent CABG, 22 were related to the coronary myocardial bridge in the left anterior 
TABLE 2. Main anatomic anomalies

\begin{tabular}{lc}
\hline Anomalies type & Number $(\%), \mathbf{n}=\mathbf{2 2 8}$ \\
\hline Anomalous muscular bundles between IVS and & \\
Ventricular apex & $178(78.1 \%)$ \\
APM & $116(50.9 \%)$ \\
PPM & $27(11.8 \%)$ \\
Adhesion to IVS or LV free wall & \\
APM & $27(11.8 \%)$ \\
PPM & $16(7.0 \%)$ \\
Accessory muscle inserted to leaflet & \\
From IVS & $5(2.2 \%)$ \\
From APM & $11(4.8 \%)$ \\
From PPM & $1(0.4 \%)$ \\
Anomalous tendinous chordae linkage to IVS & $57(25.0 \%)$ \\
APM & $71(31.1 \%)$ \\
PPM & \\
One patient may have had more than 1 anomaly. $I V S$, Interventricular septum; \\
APM, anterior papillary muscle; $P P M$, posterior papillary muscle; $L V$, left ventricle.
\end{tabular}

descending branch and 25 were ascribed to coronary atherosclerosis. Only 1 patient with myocardial bridge in the posterior descending artery had myocardial bridge unroofing. In most patients who underwent CABG because of a myocardial bridge, we used the left internal thoracic artery as a graft. The blood flow rate of most grafted left internal thoracic arteries was 15 to $20 \mathrm{~mL} / \mathrm{min}$. Compared with those in the isolated myectomy group, patients who

TABLE 3. Frequencies of concomitant procedures and early results

\begin{tabular}{lc}
\multicolumn{1}{c}{ Parameter } & $\begin{array}{c}\text { Median value or } \\
\text { number }(\mathbf{n}=\mathbf{2 7 7})\end{array}$ \\
\hline Procedures & \\
Septal myectomy alone & $150(54.15 \%)$ \\
CABG & $47(16.97 \%)$ \\
TVP & $42(15.16 \%)$ \\
MVP & $45(16.25 \%)$ \\
MVR & $14(5.05 \%)$ \\
AVR & $6(2.17 \%)$ \\
AVP & $4(1.44 \%)$ \\
Maze procedure & $18(6.50 \%)$ \\
RVOTO correction & $3(1.08 \%)$ \\
Paracardiac pheochromocytoma resection & $1(0.36 \%)$ \\
Ventricular aneurysm plication & $1(0.36 \%)$ \\
WPW pathway amputation & $3(1.08 \%)$ \\
Coronary myocardial bridge unroofing & $1(0.36 \%)$ \\
Ascending aorta replacement & $1(0.36 \%)$ \\
VSD closure & $4(1.44 \%)$ \\
In-hospital death & $2(0.72 \%)$ \\
Duration of cardiopulmonary bypass (min) & $121(\mathrm{IQR}, 102-160)$ \\
Duration of aortic crossclamping (min) & $85(\mathrm{IQR}, 67-109)$ \\
Duration of postoperative ventilation (h) & $17(\mathrm{IQR}, 14-21)$ \\
Postoperative hospital stay (d) & $8(\mathrm{IQR}, 7-11)$ \\
\hline$C A B G$, Coronary artery bypass grafting; $T V P$, tricuspid valvuloplasty; $M V P$, mitral \\
valvuloplasty; $M V R$, mitral valve replacement; $A V R$, aortic valve replacement; $A V P$, \\
aortic valvuloplasty; $R V O T O$, right ventricular outflow tract obstruction; $W P W$, Wolf- \\
Parkinson-White; $V S D$, ventricular septal defect. & \\
&
\end{tabular}

simultaneously underwent mitral operation $(P<.001)$, tricuspid valvuloplasty $(P<.001)$, and maze operation $(P=.028)$ were older. The cardiopulmonary bypass and aortic crossclamping times of the whole cohort were 121 minutes (IQR, 102-160) and 85 minutes (IQR, 67-109), respectively. Compared with patients who underwent isolated myectomy, patients who underwent concomitant operation presented significantly increased cardiopulmonary bypass time $(153$ minutes [IQR, 122-205] vs 106 minutes [IQR, 92-122], $P<.001)$ and aortic crossclamping time (106 minutes [IQR, 89-141] vs 68 minutes [IQR, 59-82], $P<.001)$.

\section{Early Results}

Two patients died early after the operation. A 60-year-old woman, who had previously undergone alcohol ablation, manifested intraoperative ventricular septal perforation because of the rupture of necrotic septal tissues. Another 59-year-old woman died of intractable postoperative low cardiac output, even though extracorporeal membrane oxygenation therapy was conducted. Iatrogenic ventricular septal defect (VSD) occurred in 4 patients, and closure with a patch via a right atrium approach was performed. One patient underwent aortic valve replacement, and 2 patients underwent aortic valvuloplasty because of iatrogenic aortic valve injury. Of the 6 patients who had preoperative right bundle branch block, only the first 3 relied on pacemaker and the remaining 3 patients had normal sinus rhythm postoperatively. A total of 6 patients received pacemaker implantation early after the operation. The postoperative ventilation time and postoperative hospital stay of the remaining patients were 17 hours (IQR, 14-21) and 8 days (IQR, 7-11), respectively. Concomitant operation also increased ventilation time (17 hours [IQR, 16-25] vs 17 hours [IQR, 13-18], $P=.019$ ) and postoperative in-hospital days (9 days [IQR, 7-13] vs 7 days [IQR, 7-9], $P<.001)$.

Before discharge, the remaining 275 patients underwent careful TTE reexamination. In comparison with those from preoperative TTE, LVOT pressure gradient decreased to $11 \mathrm{~mm} \mathrm{Hg}$ (IQR, 8-15 mm Hg) from $78 \mathrm{~mm} \mathrm{Hg}$ (IQR, 61-100 $\mathrm{mm} \mathrm{Hg}$ ), and SAM was eliminated in almost all patients, except for 2 with persistent mild SAM. Mitral regurgitation also was considerably alleviated. As shown in Table 4, left atrial diameter, ventricular septal thickness, left ventricular end-diastolic diameter, left ventricular ejection fraction, and right ventricular diameter were significantly decreased. In the last 2 years, we evaluated preoperative pro-B-type natriuretic peptide (proBNP) levels in 136 patients. The preoperative median value was $1676 \mathrm{pg} / \mathrm{mL}$ (IQR, 848-2874). At the latest follow-up, 43 patients provided their postoperative proBNP level at least 3 months after the operation. Postoperative proBNP level (647 pg/mL [IQR, 266-1080]) significantly decreased 
TABLE 4. Parameters of preoperative transthoracic echocardiography and predischarge transthoracic echocardiography

\begin{tabular}{|c|c|c|c|}
\hline Parameter & Preoperative & Predischarge & $\begin{array}{c}P \\
\text { value }\end{array}$ \\
\hline Left atrial diameter $(\mathrm{mm})$ & 44 (IQR, 40-49) & 39 (IQR, 34-43) & $<.001$ \\
\hline $\begin{array}{l}\text { Ventricular septal thickness } \\
(\mathrm{mm})\end{array}$ & 19 (IQR, 16-22) & 14 (IQR, 12-16) & $<.001$ \\
\hline $\begin{array}{l}\text { Left ventricular end-diastolic } \\
\text { diameter }(\mathrm{mm})\end{array}$ & 42 (IQR, 38-46) & 44 (IQR, 40-48) & $<.001$ \\
\hline $\begin{array}{l}\text { Left ventricular ejection } \\
\text { fraction }(\%)\end{array}$ & 73 (IQR, 68-78) & 65 (IQR, 60-70) & $<.001$ \\
\hline $\begin{array}{l}\text { Right ventricular diameter } \\
\quad(\mathrm{mm})\end{array}$ & 20 (IQR, 18-22) & 18 (IQR, 17-20) & $<.001$ \\
\hline $\begin{array}{l}\text { Main pulmonary artery } \\
\text { diameter }(\mathrm{mm})\end{array}$ & 24 (IQR, 22-26) & 23 (IQR, 21-26) & \\
\hline $\begin{array}{l}\text { LVOT pressure gradient } \\
(\mathrm{mm} \mathrm{Hg})\end{array}$ & $78(\mathrm{IQR}, 61-100)$ & 11 (IQR, 8-15) & $<.001$ \\
\hline SAM (positive/total) & $277 / 277$ & $2 / 275$ & $<.001$ \\
\hline Mitral regurgitation & & & $<.001$ \\
\hline None & 0 & 30 & \\
\hline Trace & 15 & 216 & \\
\hline Mild & 94 & 29 & \\
\hline Moderate & 144 & 0 & \\
\hline Severe & 24 & 0 & \\
\hline
\end{tabular}

$I Q R$, Interquartile range; $L V O T$, left ventricular outflow tract; $S A M$, systolic anterior motion.

compared with preoperative proBNP $(1610 \mathrm{pg} / \mathrm{mL}$ [IQR, 748-2431], $P<.001$ ).

\section{Middle-Term Results}

At the latest follow-up (14 months [IQR, 7-24]), most of the patients were in acceptable physical state. Two male patients aged 15 and 14 years died of suspected sudden cardiac arrest 15 and 16 months after the operation, respectively. The former had syncope (once) and a septal thickness of $36 \mathrm{~mm}$ preoperatively, and the latter had a septal thickness of $31 \mathrm{~mm}$ and terminated the use of beta-blocker medication after the operation without consulting a physician. Both patients underwent isolated myectomy and denied a family history of HCM and SCD. A 66-year-old male patient died of lung cancer 16 months after the operation. All 3 patients had LVOT pressure gradients less than $15 \mathrm{~mm} \mathrm{Hg}$ at the latest TTE examination and were categorized in New York Heart Association (NYHA) heart function class I when they died. The cumulative survival probability was $99.28 \%$ at 1 year and $96.98 \%$ at 5 years (Figure 3 ). Of the remaining 272 patients, 268 were classified in NYHA class I and II and 4 were classified in NYHA III and IV, and these 4 patients were aged more than 60 years. Another 2 patients underwent pacemaker implantation in the later days. No patients had accepted implantable cardioverter defibrillator (ICD) implantation, although some of them had urgent needs for SCD prevention therapy.

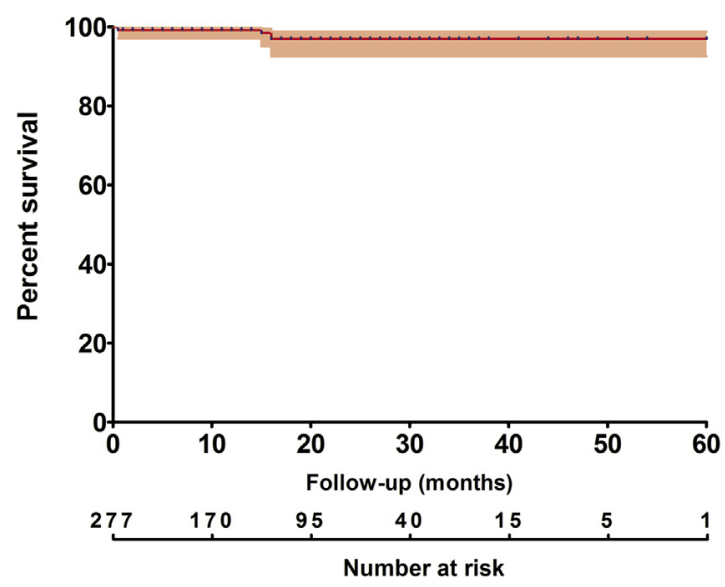

FIGURE 3. Kaplan-Meier survival chart. The cumulative survival curve of the total cohort. Red shaded area indicates $95 \%$ confidence interval.

\section{DISCUSSION}

We began to explore surgical treatment for HOCM in 2000 and started to routinely use the extended Morrow operation in 2010. ${ }^{8-10}$ Our previous retrospective report proved the favorable short-term outcome of myectomy in Chinese patients. ${ }^{9}$ To our knowledge, the present study contains the largest cohort among studies reported in Asia. However, we excluded patients aged more than 70 years. In geriatric patients, especially in elderly female patients, the ventricular septum is more fragile and brings more risk of iatrogenic VSD. Moreover, according to the study by Maron and colleagues, ${ }^{11}$ patients with HCM surviving into the seventh decade of life are at low risk for disease-related morbidity and mortality.

HOCM has been thought to be primarily induced by hypertrophic septal bulge in LVOT and has been the theoretic basis for alcohol ablation, which aimed to collapse the septal bulge by postinfarction cicatricial contraction. Primary septal myectomy mainly resected the bulge part of the hypertrophic septum. With advancements in surgery, various intraventricular anomalies were discovered, and most of them were related to mitral apparatus. ${ }^{12,13}$ Many procedures, including valve plication, papillary muscle repositioning, and secondary chordae cutting, have been reported to address mitral anomalies. ${ }^{14-16}$ Gruner and colleagues $^{17}$ reported that left ventricular apical-basal muscle bundles were detected by cardiac magnetic resonance imaging in $63 \%$ of patients with HCM. In the present study, we report a large amount of data on detailed intraventricular anomalies that were directly observed by the operator. Consistent with previous reports, our finding indicates that HCM has both myocardial dysfunction and intraventricular dysplasia. HCM is more than a kind of cardiomyopathy. The apex-IVS muscle bundles may lead to middle-LVOT or apical obstruction, whereas mitral apparatus-related anomalies participate in mitral SAM and regurgitation. Resection of IVS-apex muscle bundles 
enlarged the volume of middle and apical ventricles, which may restore the function of the apical ventricle and increase cardiac output. A study from Mayo Clinic suggested that surgical myectomy decreased the risk for lethal arrhythmias despite the mean resting gradient of only $17.4 \pm 25 \mathrm{~mm} \mathrm{Hg}$ in the control group. ${ }^{18}$ This result indicates that relief of LVOT obstruction is not the only reason for myectomy-induced decrease in SCD incidence. The unconfirmed contributory factors may include the removal of anomalous muscles, considering that papillary muscles contain abundant Purkinje fibers and are an important origin of ventricular arrhythmias. However, further investigations are necessary to uncover the relationship between anomalous muscle bundles and SCD. We believe that adequate length of septal excision is extremely important to surgical effect. It has been reported that an inadequate length of septal excision was the most common cause of recurrent LVOT obstruction after myectomy. ${ }^{19}$ We used long-handled forceps and scalpels to ensure an adequate length of resection. Intraoperative measurement of LVOT gradient could assist the surgeon in defining the extent of myectomy. ${ }^{20}$

Approximately half of the patients in the present cohort underwent concomitant procedures. In most cases, mitral dysfunction disappeared after extended myectomy, including removal of anomalous muscle bundles and tendinous chordae. However, for mitral valves with other structural lesions and pathologic changes, especially in patients aged more than 60 years, additional mitral repair should be performed. If the lesion or anomaly is irreparable or mitral repair greatly increases cardiopulmonary bypass time, mitral replacement should be immediately performed. Coronary disease is another common concomitant cardiomyopathy of HCM and leads to poor long-term prognosis. ${ }^{21,22}$ Coronary myocardial bridge was detected in approximately $15 \%$ of the patients in the present cohort, and the proportion was lower than that reported from a study in Canada. ${ }^{23}$ Because unroofing has been proven safe with satisfactory pleasurable short-term outcomes, ${ }^{24}$ we are shifting to unroofing therapy for appropriate patients.

Left bundle branch block, iatrogenic VSD, and aortic valve injury are the main complications of transaortic septal myectomy. In the present cohort, pacemaker implantation incidence $(2.90 \%)$ was satisfactory. This incidence was attributed to the adoption of conservative surgical strategies in patients with preoperative right bundle branch block, although it led to a slightly higher residual gradient of up to $20 \mathrm{~mm} \mathrm{Hg}$ in some patients. However, we believe that avoiding pacemaker implantation could result in additional benefits to long-term outcomes and quality of life, especially in young patients. In principle, aortic valve injury and iatrogenic VSD were prone to occur in young patients with small aortic roots and old patients with an
IVS thickness of approximately $18 \mathrm{~mm}$, respectively. A recent study also suggested that prior alcohol septal ablation was related to worse outcomes after myectomy. ${ }^{25}$ However, another study suggested that alcohol septal ablation did not independently affect outcomes. ${ }^{26}$ Patients with HOCM may obtain increased benefits in experienced heart centers, where cardiologists could have close communication with experienced surgeons and provide the patients with reasonable advice about alcohol ablation treatment.

Progressive heart failure and SCD are the 2 main disastrous outcomes of HCM. HCM-related heart failure can be prevented or delayed by medication after the operation, and few patients may need heart transplantation. As the most common cause of SCD in young population, HCM induces SCD mainly by fatal ventricular arrhythmia, which could be converted by ICD. ${ }^{27} \mathrm{HCM}$-induced SCD is widely related to multiple factors. ${ }^{5,6}$ Surgical myectomy aimed to relieve LVOT obstruction was proven to reduce the incidence of appropriate ICD discharge and risk for SCD. ${ }^{18}$ Nevertheless, treatment of young patients with obstructive HCM remains challenging for physicians in at least 2 aspects. First, surgical operation on a growing heart offers extra difficulties because of poor exposure and limited operating space via the aorta. Furthermore, patients undergoing myectomy at a younger age are supposed to have rapid progression of disease and extra SCD risk. Therefore, postoperative medication and SCD prevention may be important for young patients. However, the high cost of ICD and low consultation rates place SCD prevention in an awkward position in China.

In recent years, septal myectomy has developed into a comprehensive repair of anomalous LVOT. Similar to the results from North America and Europe, ${ }^{23,28-32}$ our study proved that myectomy performed in experienced centers is a safe and effective strategy for medication-refractory patients with obstructive HCM. Short- and medium-term outcomes are satisfying. Moreover, consistent with previous reports, ${ }^{28,30}$ concomitant operations do not greatly increase additional lethal risk. An experienced team consisting of fixed members may be a key factor to safety.

\section{Study Limitations}

The present study, limited by the short follow-up, could not demonstrate the long-term improvement. Recurrent valvular insufficiency and LVOT obstruction were not clearly determined. Anatomic description was highly dependent on intraoperative inspection, and it needed systemic imaging and pathologic studies. The lack of an appropriate control group and complete follow-up examinations also limited further analyzing the role of intraventricular anomalies. Deficiency of necessary preoperative examinations, such as cardiac magnetic resonance imaging, was another important limitation. The 
retrospective and single-operator design might have incurred selection bias.

In conclusion, extended septal myectomy is effective and safe for patients with HOCM. Intraventricular anomalies are common in these patients. Excision of anomalous muscle bundles should be an important addition to septal myectomy.

\section{Conflict of Interest Statement}

Authors have nothing to disclose with regard to commercial support.

\section{References}

1. Maron BJ, Gardin JM, Flack JM, Gidding SS, Kurosaki TT, Bild DE. Prevalence of hypertrophic cardiomyopathy in a general population of young adults. Echocardiographic analysis of 4111 subjects in the CARDIA Study. Coronary Artery Risk Development in (Young) Adults. Circulation. 1995;92:785-9.

2. Zou Y, Song L, Wang Z, Ma A, Liu T, Gu H, et al. Prevalence of idiopathic hypertrophic cardiomyopathy in China: a population-based echocardiographic analysis of 8080 adults. Am J Med. 2004;116:14-8.

3. Maron BJ, Doerer JJ, Haas TS, Tierney DM, Mueller FO. Sudden deaths in young competitive athletes: analysis of 1866 deaths in the United States, 1980-2006. Circulation. 2009;119:1085-92.

4. Maron BJ, Haas TS, Murphy CJ, Ahluwalia A, Rutten-Ramos S. Incidence and causes of sudden death in U.S. college athletes. J Am Coll Cardiol. 2014;63: 1636-43.

5. Gersh BJ, Maron BJ, Bonow RO, Dearani JA, Fifer MA, Link MS, et al. 2011 ACCF/AHA guideline for the diagnosis and treatment of hypertrophic cardiomyopathy: a report of the American College of Cardiology Foundation/ American Heart Association Task Force on Practice Guidelines. Circulation. 2011;124:e783-831.

6. Elliott PM, Anastasakis A, Borger MA, Borggrefe M, Cecchi F, Charron P, et al. 2014 ESC Guidelines on diagnosis and management of hypertrophic cardiomyopathy: the Task Force for the Diagnosis and Management of Hypertrophic Cardiomyopathy of the European Society of Cardiology (ESC) Eur Heart J. 2014;35:2733-79.

7. Dearani JA, Ommen SR, Gersh BJ, Schaff HV, Danielson GK. Surgery insight: septal myectomy for obstructive hypertrophic cardiomyopathy-the Mayo Clinic experience. Nat Clin Pract Cardiovasc Med. 2007:4:503-12.

8. Cui B, Wang S, Xu J, Wang W, Song Y, Sun H, et al. The surgical management of hypertrophic obstructive cardiomyopathy with the concomitant mitral valve abnormalities. Interact Cardiovasc Thorac Surg. 2015;21:722-6.

9. Wang S, Luo M, Sun H, Song Y, Yin C, Wang L, et al. A retrospective clinical study of transaortic extended septal myectomy for obstructive hypertrophic cardiomyopathy in China. Eur J Cardiothorac Surg. 2013;43:534-40.

10. Wang SY, Cui B, Sun HS, Song YH, Sun LZ, Xu JP, et al. [Clinical experience of surgical treatment on hypertrophic obstructive cardiomyopathy]. Zhonghua $Y i$ Xиe Za Zhi. 2009;89:2776-8.

11. Maron BJ, Rowin EJ, Casey SA, Haas TS, Chan RHM, Udelson JE, et al. Risk stratification and outcome of patients with hypertrophic cardiomyopathy $>=60$ years of age. Circulation. 2013;127:585-93.

12. Minakata K, Dearani JA, Nishimura RA, Maron BJ, Danielson GK Extended septal myectomy for hypertrophic obstructive cardiomyopathy with anomalous mitral papillary muscles or chordae. J Thorac Cardiovasc Surg. 2004;127:481-9.

13. Kaple RK, Murphy RT, DiPaola LM, Houghtaling PL, Lever HM, Lytle BW, et al. Mitral valve abnormalities in hypertrophic cardiomyopathy: echocardiographic features and surgical outcomes. Ann Thorac Surg. 2008;85:1527-35, 1535.e1-2.

14. Balaram SK, Ross RE, Sherrid MV, Schwartz GS, Hillel Z, Winson G, et al Role of mitral valve plication in the surgical management of hypertrophic cardiomyopathy. Ann Thorac Surg. 2012;94:1990-8.
15. Redaelli M, Poloni CL, Bichi S, Esposito G. Modified surgical approach to symptomatic hypertrophic cardiomyopathy with abnormal papillary muscle morphology: Septal myectomy plus papillary muscle repositioning. J Thorac Cardiovasc Surg. 2014;147:1709-11.

16. Ferrazzi P, Spirito P, Iacovoni A, Calabrese A, Migliorati K, Simon G, et al. Transaortic chordal cutting: mitral valve repair for obstructive hypertrophic cardiomyopathy with mild septal hypertrophy. J Am Coll Cardiol. 2015;66:1687-96.

17. Gruner C, Chan RH, Crean A, Rakowski H, Rowin EJ, Care M, et al. Significance of left ventricular apical-basal muscle bundle identified by cardiovascular magnetic resonance imaging in patients with hypertrophic cardiomyopathy. Eur Heart J. 2014;35:2706-13.

18. McLeod CJ, Ommen SR, Ackerman MJ, Weivoda PL, Shen WK, Dearani JA, et al. Surgical septal myectomy decreases the risk for appropriate implantable cardioverter defibrillator discharge in obstructive hypertrophic cardiomyopathy. Eur Heart J. 2007:28:2583-8.

19. Cho YH, Quintana E, Schaff HV, Nishimura RA, Dearani JA, Abel MD, et al Residual and recurrent gradients after septal myectomy for hypertrophic cardiomyopathy-mechanisms of obstruction and outcomes of reoperation. $J$ Thorac Cardiovasc Surg. 2014;148:909-16.

20. Ashikhmina EA, Schaff HV, Ommen SR, Dearani JA, Nishimura RA, Abel MD Intraoperative direct measurement of left ventricular outflow tract gradients to guide surgical myectomy for hypertrophic cardiomyopathy. J Thorac Cardiovasc Surg. 2011;142:53-9.

21. Cecchi F, Olivotto I, Gistri R, Lorenzoni R, Chiriatti G, Camici PG. Coronary microvascular dysfunction and prognosis in hypertrophic cardiomyopathy N Engl J Med. 2003;349:1027-35.

22. Sorajja P, Ommen SR, Nishimura RA, Gersh BJ, Berger PB, Tajik AJ. Adverse prognosis of patients with hypertrophic cardiomyopathy who have epicardial coronary artery disease. Circulation. 2003;108:2342-8.

23. Parry DJ, Raskin RE, Poynter JA, Ribero IB, Bajona P, Rakowski H, et al. Short and medium term outcomes of surgery for patients with hypertrophic obstructive cardiomyopathy. Ann Thorac Surg. 2015;99:1213-9.

24. Kunkala MR, Schaff HV, Burkhart H, Sandhu GS, Spoon DB, Ommen SR, et al. Outcome of repair of myocardial bridging at the time of septal myectomy. Ann Thorac Surg. 2014;97:118-23.

25. Quintana E, Sabate-Rotes A, Maleszewski JJ, Ommen SR, Nishimura RA, Dearani JA, et al. Septal myectomy after failed alcohol ablation: does previous percutaneous intervention compromise outcomes of myectomy? J Thorac Cardiovasc Surg. 2015;150:159-67.e1.

26. Desai MY, Smedira NG, Bhonsale A, Thamilarasan M, Lytle BW, Lever HM. Symptom assessment and exercise impairment in surgical decision making in hypertrophic obstructive cardiomyopathy: relationship to outcomes. J Thorac Cardiovasc Surg. 2015;150:928-35.e1.

27. Maron BJ, Spirito P, Shen WK, Haas TS, Formisano F, Link MS, et al Implantable cardioverter-defibrillators and prevention of sudden cardiac death in hypertrophic cardiomyopathy. JAMA. 2007;298:405-12.

28. Ross RE, Sherrid MV, Casey MM, Swistel DG, Balaram SK. Does surgical relief of obstruction improve prognosis for hypertrophic cardiomyopathy? Prog Cardiovasc Dis. 2012:54:529-34.

29. Sedehi D, Finocchiaro G, Tibayan Y, Chi J, Pavlovic A, Kim YM, et al. Long-term outcomes of septal reduction for obstructive hypertrophic cardiomyopathy. J Cardiol. 2015;66:57-62.

30. Desai MY, Bhonsale A, Smedira NG, Naji P, Thamilarasan M, Lytle BW, et al. Predictors of long-term outcomes in symptomatic hypertrophic obstructive cardiomyopathy patients undergoing surgical relief of left ventricular outflow tract obstruction. Circulation. 2013:128:209-16.

31. Iacovoni A, Spirito P, Simon C, Iascone M, Di Dedda G, De Filippo P, et al A contemporary European experience with surgical septal myectomy in hypertrophic cardiomyopathy. Eur Heart J. 2012;33:2080-7.

32. Steggerda RC, Damman K, Balt JC, Liebregts M, ten Berg JM, van den Berg MP. Periprocedural complications and long-term outcome after alcohol septal ablation versus surgical myectomy in hypertrophic obstructive cardiomyopathy. JACC Cardiovasc Interv. 2014;7:1227-34.

Key Words: hypertrophic obstructive cardiomyopathy, septal myectomy, anomalous muscle bundles 